\title{
National NIF Diagnostic Program Fiscal Year 2002 Second Quarter Report
}

\author{
B. MacGowan
}

April 1, 2002

U.S. Department of Energy

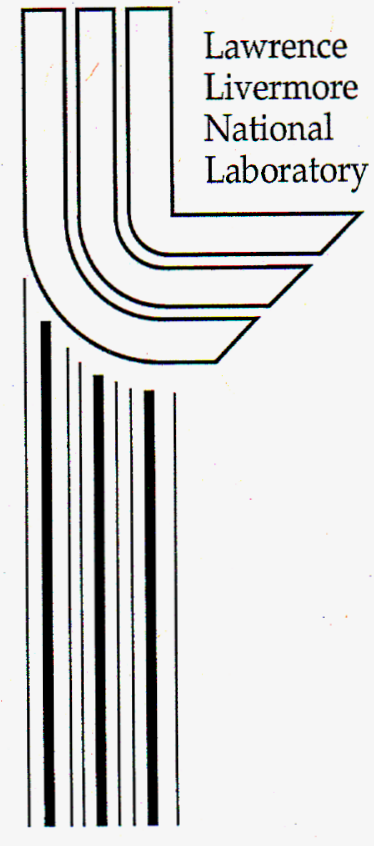




\section{National NIF Diagnostic Program Fiscal Year 2002 Second Quarter Report}

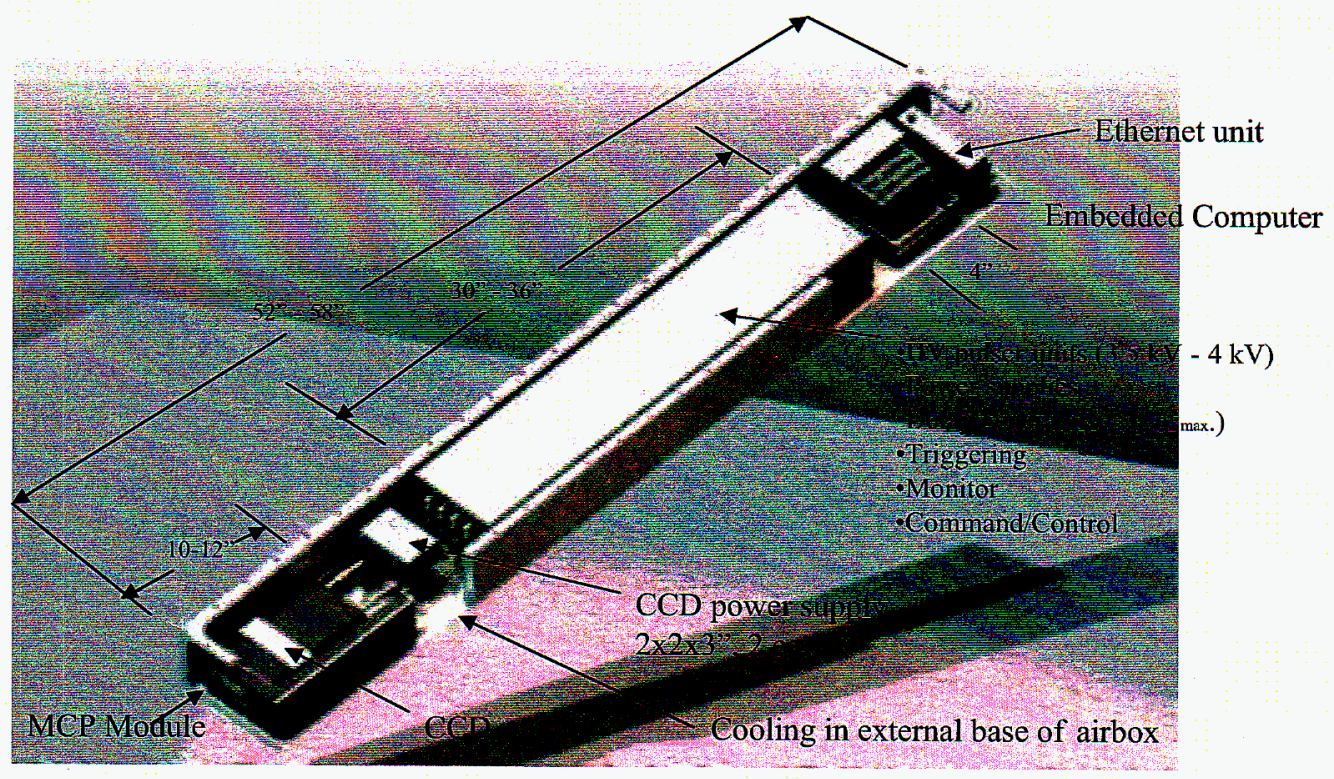

April 2002

Lawrence Livermore

National Laboratory

7000 East Avenue

Livermore, CA 94550 
TABLE OF CONTENTS

OVERVIEW AND SUMMARY .....................................................................

SCHEDULE REPORT ....................................................................................... 1

BUDGET REPORT .................................................................................2

CHANGE CONTROL BOARD ACTIONS ........................................................

STREAKED X-RAY DETECTOR (SXD) ...................................................

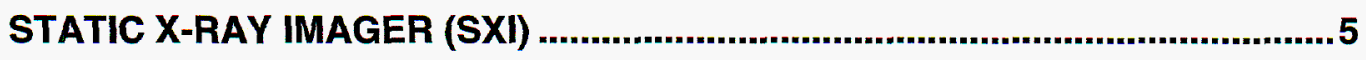

FULL APERTURE BACKSCATTER DIAGNOSTICS (FABS) ...........................5

DIM POSITIONER SYSTEM (DPS) ...........................................................

GATED X-RAY DETECTOR (GXD) …......................................................

X-RAY SURVEY SPECTROMETER (HENEX) ...........................................

VISAR .........................................................................................................

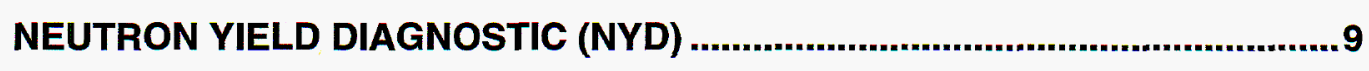

TARGET DIAGNOSTIC INTEGRATION .....................................................10

CONTROLS INTEGRATION ....................................................................... 12 


\section{National NIF Diagnostics Program FY02 Second Quarter Report April 2002}

\section{Overview and Summary}

Since October 2001 the development of the facility diagnostics for NIF has been funded by the NIF Director through the National NIF Diagnostic Program (NNDP). The current emphasis of the NNDP is on diagnostics for the early NIF quad scheduled to be available for experiment commissioning in FY03. During the past six months the NNDP has set in place processes for funding diagnostics, developing requirements for diagnostics, design reviews and monthly status reporting. Those processes are described in an interim management plan for diagnostics $(\mathrm{Na}$ tional NIF Diagnostic Program Interim Plan, NIF-0081315, April 2002) and a draft Program Execution Plan (Program Execution Plan for the National NIF Diagnostic Program, NIF0072083, October 2001) and documents cited therein. Work has been funded at Lawrence Livermore National Laboratory (LLNL), Los Alamos National Laboratory (LANL), Naval Research Laboratory (NRL), Sandia National Laboratories (SNL), Bechtal Nevada at Los Alamos and Santa Barbara. There are no major technical risks with the early diagnostics. The main concerns relate to integration of the diagnostics into the facility, all such issues are being worked. This report is organized to show the schedule and budget status and a summary of Change Control Board actions for the past six months. The following sections then provide short descriptions of the status of each diagnostic. Where design reviews or requirements documents are cited, the documents are available on the Diagnostics file server or on request.

\section{Schedule Report}

The table below summarizes the status of the Level 3 milestones for the Facility Diagnostics. The plan date refers to the target date in the Control Account Plan for each diagnostic. Although some near-term milestones have slipped relative to plan (e.g., for SXI), final delivery dates of the diagnostics are still consistent with the first quad schedule. The slippage has been mainly in executing design reviews as the deliverables and processes have evolved. Some procurements have also been delayed due to delays in funding at the start of the year. The M6 dates (shown in yellow) correspond to the first date that the diagnostic or manipulator will be available for use on NIF for either laser commissioning or experiment commissioning. In general, the final delivery date is being maintained, however, the FABS delivery dates have been delayed slightly through a Budget/Schedule Change Request (BSCR) action. This step was taken to make the schedule consistent with the delay in the FABS component procurements. 
Table 1: Status of Level 3 milestones for the facility diagnostics.

\begin{tabular}{|c|c|c|c|c|}
\hline Diagnostic & Deliverable( $\square$ completed) & Ievel & Plan Date & $\begin{array}{c}\text { Projected/ } \\
\text { actual } \\
\text { completion }\end{array}$ \\
\hline HENEX & HENEX $100 \%$ design review complete & 3 & Sep-01 & Nov-01 \\
\hline SXI & SXI $100 \%$ design review complete & 3 & Oct-01 & Nov-01 \\
\hline FABS-LRU & FABS-LRU 65\% Design Review complete & 3 & Dec-01 & Jan-02 \\
\hline FABS & FABS $65 \%$ Design Review complete & 3 & Nov-01 & Jan-02 \\
\hline SXD & $65 \%$ design review complete & 3 & $\operatorname{Jan}-02$ & Feb-02 \\
\hline FABS-LRU & FABS-LRU 100\% Design Review complete & 3 & Feb-02 & Mar-02 \\
\hline GXD & Conceptual design review complete & 3 & Apr-02 & Apr-02 \\
\hline NY & Requirements Review complete & 3 & Apr-02 & Apr-02 \\
\hline SXD & $100 \%$ design review complete & 3 & Mar-02 & May-02 \\
\hline VISAR & Conceptual design review complete & 3 & Jun-02 & Jun-02 \\
\hline SXD & First streak camera delivered & 3 & Aug-02 & Aug-02 \\
\hline$S X$ & SXI-1 Fab \& Assembly Complete & 3 & May-02 & Aug-02 \\
\hline FABS & FABS $100 \%$ Design Review & 3 & Sep-02 & Sep-02 \\
\hline DIM & 2nd DIM Fabrication \& Assembly (M4A) & 3 & Sep-02 & Sep-02 \\
\hline NY & Conceptual design review complete & 3 & Sep-02 & Sep-02 \\
\hline GXD & $65 \%$ design review complete & 3 & Sep-02 & Sep-02 \\
\hline SXI & SXI-1 Offline acceptance tests Complete & 3 & Aug-02 & Sep-02 \\
\hline SXD & 2nd streak camera delivered & 3 & Oct-02 & Oct-02 \\
\hline FABS-LRU & Deliver FABS LRUs to OAB & 3 & Nov-02 & Nov-02 \\
\hline DIM & 3rd DIM Fabrication \& Assembly (M4A) & 3 & Nov-02 & Nov-02 \\
\hline DIM & 2nd DIM ready for use on NIF (M6) & 3 & Jan-03 & Jan-03 \\
\hline SXD & SXD-1 1st Use on NIF (M6) & 3 & Jan-03 & Jan-03 \\
\hline SXI & SXI-1 1st Use on NIF (M6) & 3 & Jan-03 & Jan-03 \\
\hline DIM & 3rd DIM ready for use on NIF (M6) & 3 & Feb-03 & Feb-03 \\
\hline FABS & FABS 1 First Use on NIF (M6) & 3 & Jul-03 & Jul-03 \\
\hline VISAR & First use on NIF (M6) & 3 & Jul-03 & Jul-03 \\
\hline HENEX & First use on NIF (M6) & 3 & Dec-03 & Dec-03 \\
\hline
\end{tabular}

\section{Budget Report}

Figure 1 summarizes the status of spending against the FY02 Budget Authority of $\$ 8857 \mathrm{~K}$.

Commitment of funds is lagging behind plan due to late starts at some of the non-LLNL sites, as a consequence of delays in funding. Some procurements have also been delayed slightly from their planned dates with little effect on final diagnostic delivery dates. It is anticipated that by the next quarter, the late procurements $(\sim 900 \mathrm{~K})$ will have been processed and we will be closer to our Budget Authority (BA) plan. BSCRs have been processed to transfer predicted underspending in the FABS diagnostic to allow acceleration of the diagnostic manipulators. Figure 2 
illustrates the same information for costs (Budget Outlay [BO]); the delay in placing some procurements will result in a reduction in BO projected relative to plan near the end of this FY.

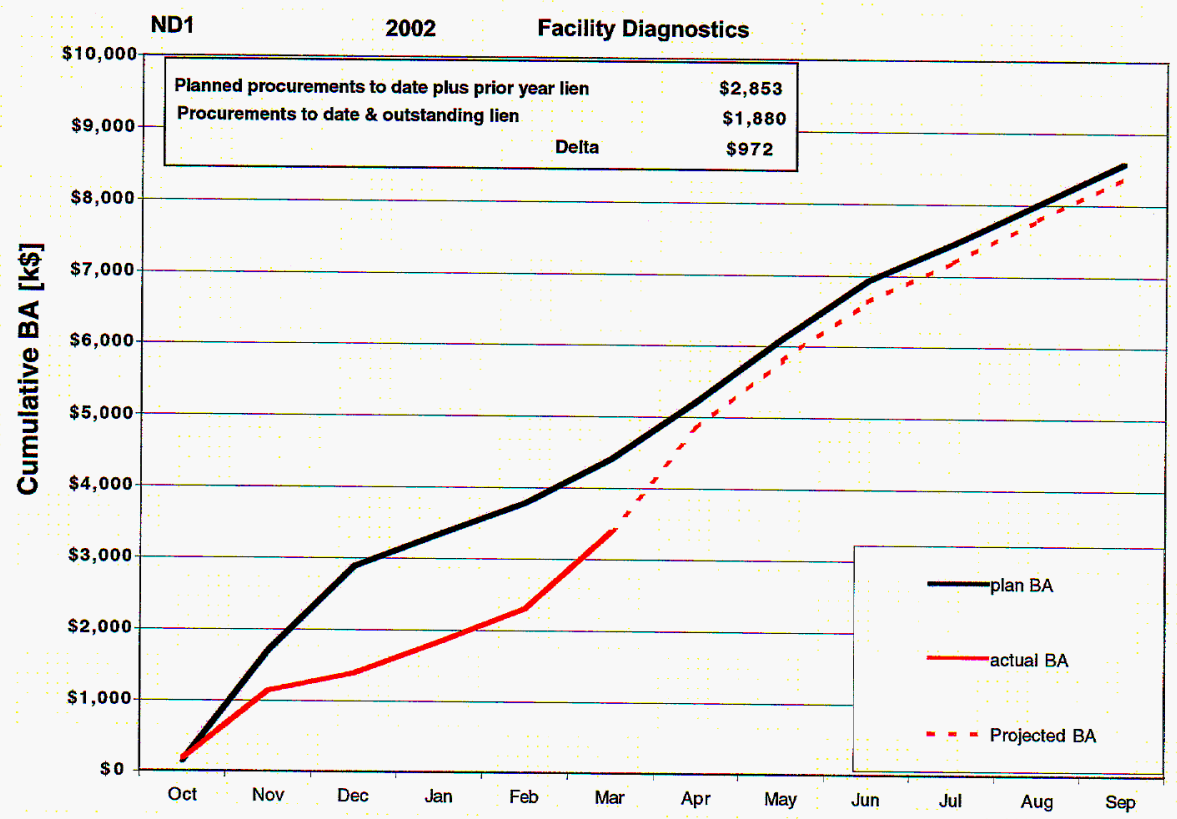

Figure 1: Status of commitment of resources (BA) against the FYO2 plan for the Facility Diagnostics.

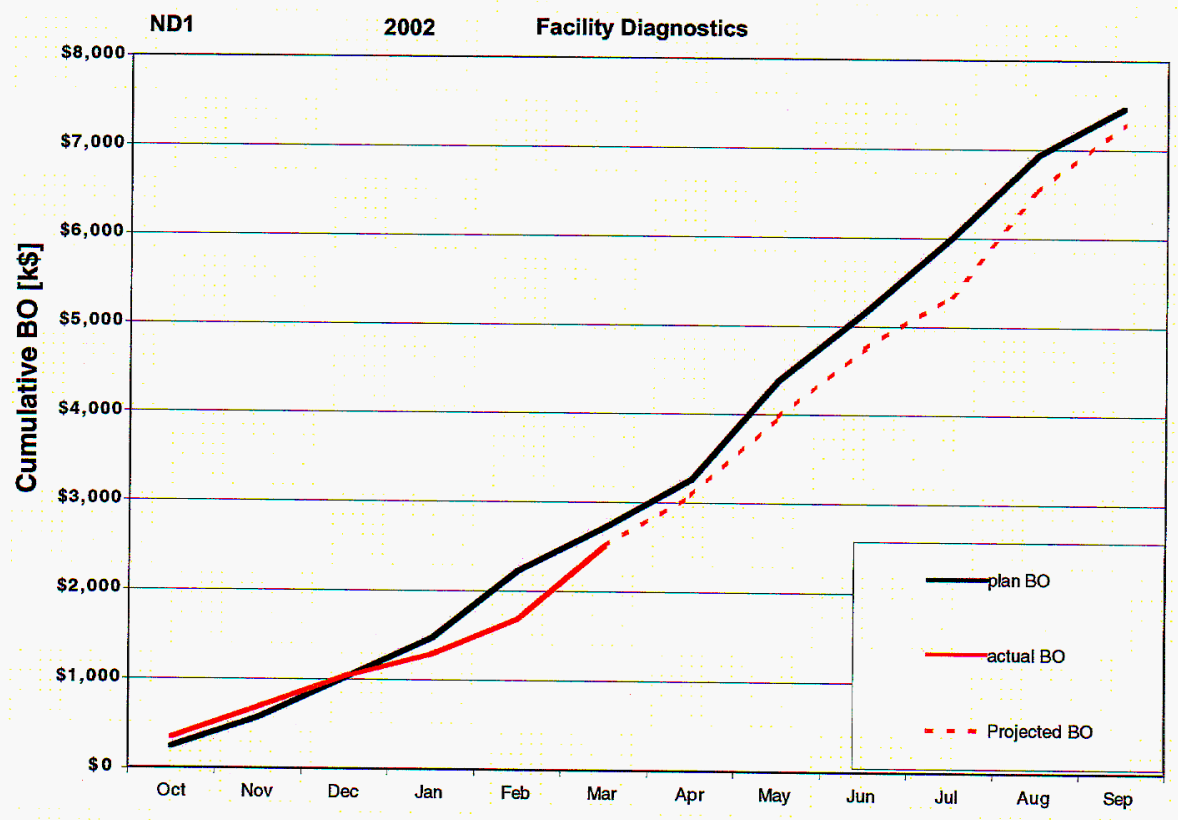

Figure 2: Status of costs (BO) against the FY02 plan for the Facility Diagnostics. 


\section{Change Control Board Actions}

BSCR-001: Increased the scope and budget for the VISAR to fund activities through the end of FY02. The original Control Account Plan (CAP) planned only through a Conceptual Design Report (CDR) completed in June.

BSCR-002: Increased the scope and budget for the Diagnostic Instrument Manipulators (DIM) to adequately fund the fielding of a DIM on the upper pole of the target chamber, including testing, and facility modifications required. This change also increased the number of DIMs procured in FY02 to two, with the goal of providing greater capability for diagnostics commissioning in FY03.

BSCR-003: Decreased the scope and budget of the FABS in FY02 consistent with a delivery date of July 2003 for the finished diagnostic.

BSCR-004: Decremented the budget of the NNDP integration CAP to transfer money to fund VISAR and the DIMs.

\section{Streaked X-Ray Detector (SXD)}

The $65 \%$ review was completed and accepted. In addition, the air-box and a standard mounting assembly for snouts were designed and approved. Solicitations were put out for bids for machining both. The basic design for mounting the diagnostic to the DIM cart is being compared to an alternative design. Both appear equivalent and are out for cost estimates. The cheaper design will be used.

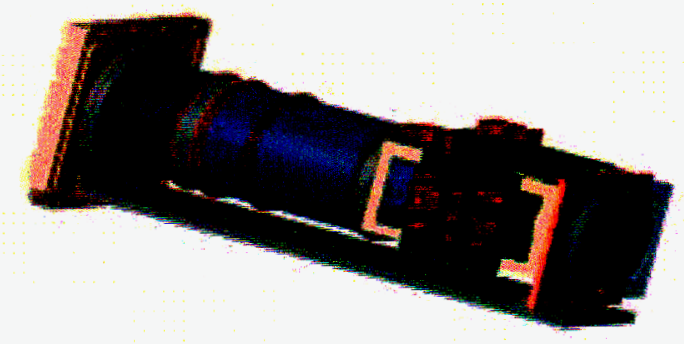

a)

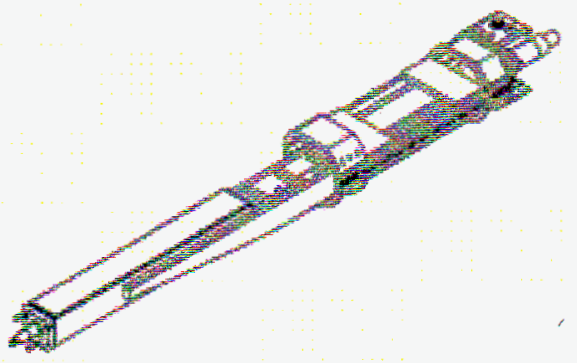

b)

Figure 3a) CAD model of DRS Hadland sireak camera from 65\% design review, $b$ ) drawing of SXD airbox mounted in DIM cart with low magnification imaging snout.

The SXD is designed to utilize a short pulse $4 \omega$ timing fiducial injected through a fiber optic. This timing signal together with monitoring of operating voltages and taking dark field images with the charge-coupled device (CCD) will enhance reliability by showing that components are functional and operating prior to each shot. Although the $4 \omega$ signal will not be available when SXD is first used on NIF in early 2003 it will be utilized by SXD in the mid-FY04 timeframe. In addition to installing the ability to use the $4 \omega$ fiducial, the contracting vendor, Hadland, is estimating the costs to implement a slow sweep to aid in flat field calibration. Hadland sent an Ap- 
plication Programming Interface document describing the proposed set of commands, and our software group is working with them on the details. Within the next month the software effort should ramp up and we should build the user interface.

Hadland is scheduled for a $100 \%$ design review in May and delivery of hardware in August.

\section{Static X-Ray Imager (SXI)}

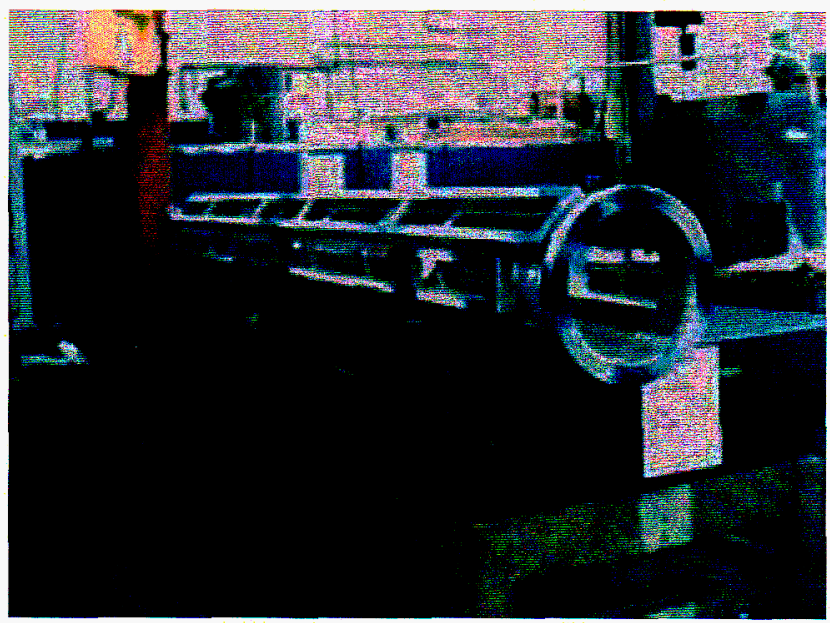

Figure 4: Part of the Static X-ray Imager manipulator section during fabrication.

In the last quarter, the SXI achieved all of its required technical objectives. The procurement packages were prepared and awarded. The back-illuminated CCD detector was fully assembled, tested, and calibrated at Brookhaven. The proposal to move the SXIs to their new locations was approved by the NIF Level 4 Change Control Board. The moves were required to reduce conflicts between target chamber equipment and the body of the SXI. The control software is currently in the late testing phase of development. At this time, the major concerns are making the limit switch system more robust, finalizing the alignment procedure, and working through installation and fielding issues on the facility including synchronizing with the target area schedule.

\section{Full Aperture Backscatter Diagnostics (FABS)}

The Full Aperture Backscatter (FABS) diagnostic is used to analyze scattered laser light originating from the NIF Target Chamber to characterize the energy coupling between the Laser and NIF Targets. The FABS diagnostic $65 \%$ design review was completed in the last quarter. A measurement calibration strategy was developed, and a streak camera was selected for initial fielding of the diagnostic by July 2003. Streak camera performance and measurement dynamic range are technical concerns, which are being worked by extensive characterization of candidate cameras by the ICF Program. The schedule and budget for the project are currently being updated to be consistent with a July 2003 delivery date and were the subject of a BSCR. 


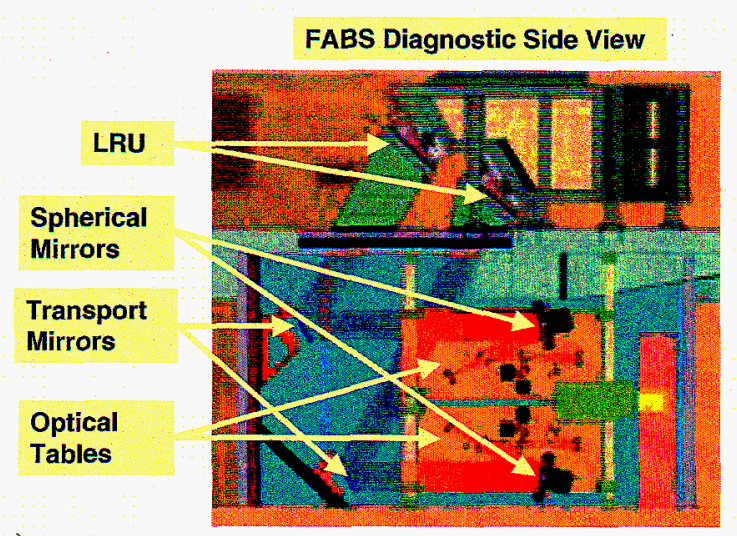

a)

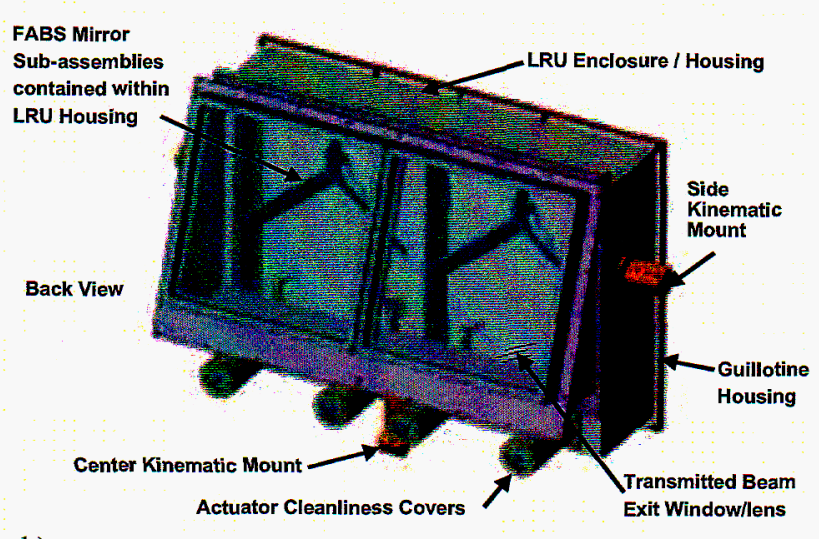

b)

Figure 5a) CAD model of layout of FABS diagnostic in the basement of the target area, b) CAD model of FABS LM8 mirror (LRU) assembly from $100 \%$ design review.

The FABS measurement requires a direct line-of-sight between the NIF target, through the final transport laser mirrors (LM8), and onto the diagnostic. The FABS line replaceable units (LRUs) have been specifically designed to support the LM8 mirrors, while providing the necessary lineof-sight and occluding less than $15 \%$ of the desired backscattered light. Since the mirrors are need for commissioning the first NIF beamlines the LRU part of the FABS has been on an accelerated schedule. During the past quarter the design of the LM8 LRU for the FABs went through its $65 \%$ and $100 \%$ design reviews. The reviews demonstrated that:

- The actuator design used to position mirrors meets NIF linearity and hysteresis requirements.

- Finite element analysis of the FABS LRU and mirror subassembly is consistent with the LM8 LRUs and standard transport mirrors (LM4-8), meeting NIF requirements.

- Darkening parts of the mirror substrate by selectively solarizing the glass is effective at shielding the mechanical hardware supporting the mirror from the potentially very high fluences associated with the laser light backreflections.

The FABS LM8 LRU also completed a procurement review on 1/30/02 with the full set of drawings complete and under configuration management on 4/19/02. While drawing completion slipped from April 1, receipt of the first FABS components remains on schedule for August 16, 2002.

\section{DIM Positioner System (DPS)}

In the last quarter, all of the technical objectives associated with the DIM have been achieved. The procurement package for two DIMs was awarded for delivery at the end of this FY. The first article DIM has been fully assembled and aligned and is now undergoing testing. A potential problem with the ballscrew drive mechanism being susceptible to back-driving was identified and a solution designed. Other concerns over the robustness of the limit switch system are being addressed. The platforms for the polar DIM were designed; these platforms will allow effective 
use of the DIM to be mounted on the top pole of the target chamber. The schedule of installation of the DIMs is being synchronized with that of the target area as a whole.

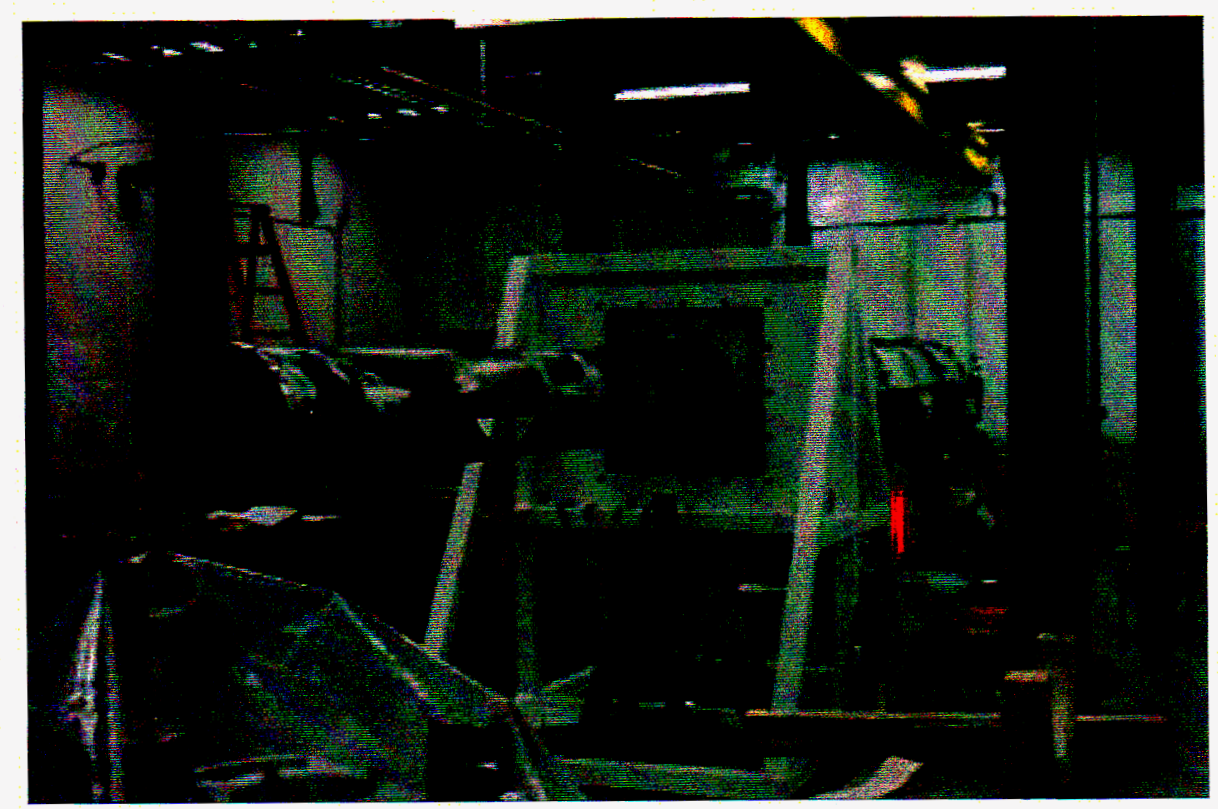

Figure 6: First article DIM undergoing testing

\section{Gated X-Ray Detector (GXD)}

On April 23, 2002, LANL completed the Conceptual Design Review (CDR/M1) for the Gated $\mathrm{X}$-ray Detector (GXD). LANL has had a late start, but is catching up quickly with the help of increased staffing and improved communications with LLNL NIF personnel. Discussions have begun with the major vendors that will supply the gate pulsers, CCD cameras, and embedded computers. These discussions have raised concerns as to the feasibility of accommodating all the GXD functions while retaining the capability to fit into a standard 45" DIM airbox. There were two specifications realized in the CDR that need to be modified by the formal specification change process. LANL expects to have the long lead time procurements specified and requests for quotation sent out by July 2002. The 65\% design review is scheduled for September 2002. 


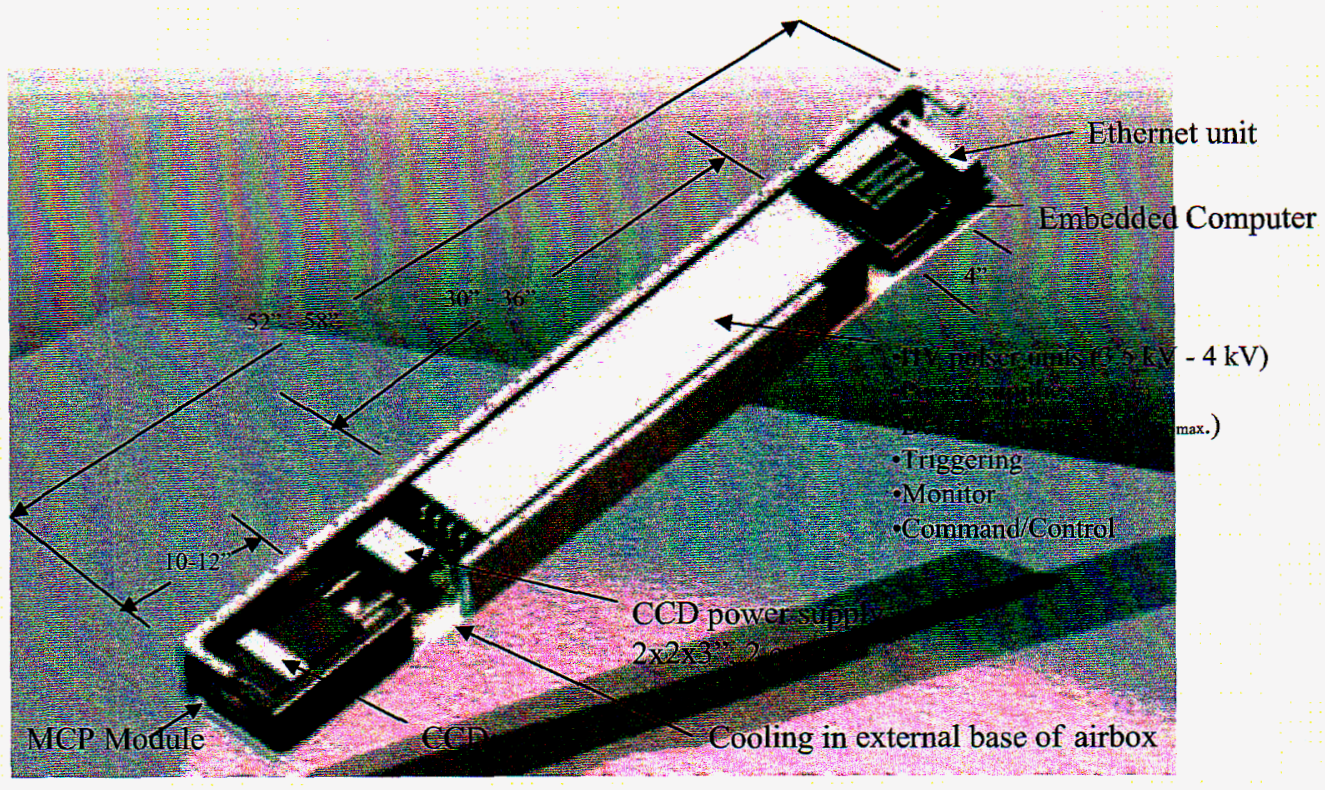

Figure 7: CAD model of the packaging planned for the gated $x$-ray detector (GXD) within an extended DIMmountable airbox

\section{X-Ray Survey Spectrometer (HENEX)}

The HENEX 100\% Design Review was held on 8 November 2001. Delays in transferring funds to NRL have caused a delay in the fabrication and procurement of the HENEX parts. The schedule delay will be made up through reducing the amount of time devoted to off-line testing at Omega in FY03. In preparation for HENEX fabrication, the mechanical CAD drawings were sent out for cost quotation in April. Meanwhile, some HENEX component testing has been performed at the Laboratory for Laser Energetics (LLE), where on 10 January 2002, bright 13-keV krypton spectra were recorded by a transmission crystal similar to the one planned for HENEX.

\section{VISAR}

Funding arrived, and design of the NEL VISAR began in late January. In general, work is proceeding on schedule. The exception is the definition of facility impacts, a process that is requiring significant iteration between NIF integration designers and the BN optical engineers. A general system layout has been developed, and the conceptual design of system components, such as the fiber delivery system and interferometer design, is ongoing.

The probe laser requirements were prepared and submitted to NNDP management on March 6. The probe laser is a long-lead-time item, as well as expensive. It was essential to carefully determine specifications for the laser early in the project, before most of the system design was completed on a conceptual level, and submit the laser for bid. The laser specified is a 1.2microsecond $60-\mathrm{kW}$ pulsed coherent light source with a fixed wavelength in the range of 575 to $675 \mathrm{~nm}$. 
An optical relay system has been designed to transport a target image to a streak camera about 120 feet away. The design was constrained by small apertures in the DIM, the potential interference of the DIM cable tray, obstacles in the physical path through the facility, and the desire for $\mathrm{f} / 3$ collection. The current design accommodates $\mathrm{f} / 3$ collection for $1-5 \mathrm{~mm}$ objects and $\mathrm{f} / 6 \mathrm{col}-$ lection for 10-mm objects with no vignetting. The exact path for the optical relay through the facility has not been determined, but the optical design is flexible and will likely fit the path without significant modifications. The conceptual design review for the VISAR is scheduled for June.

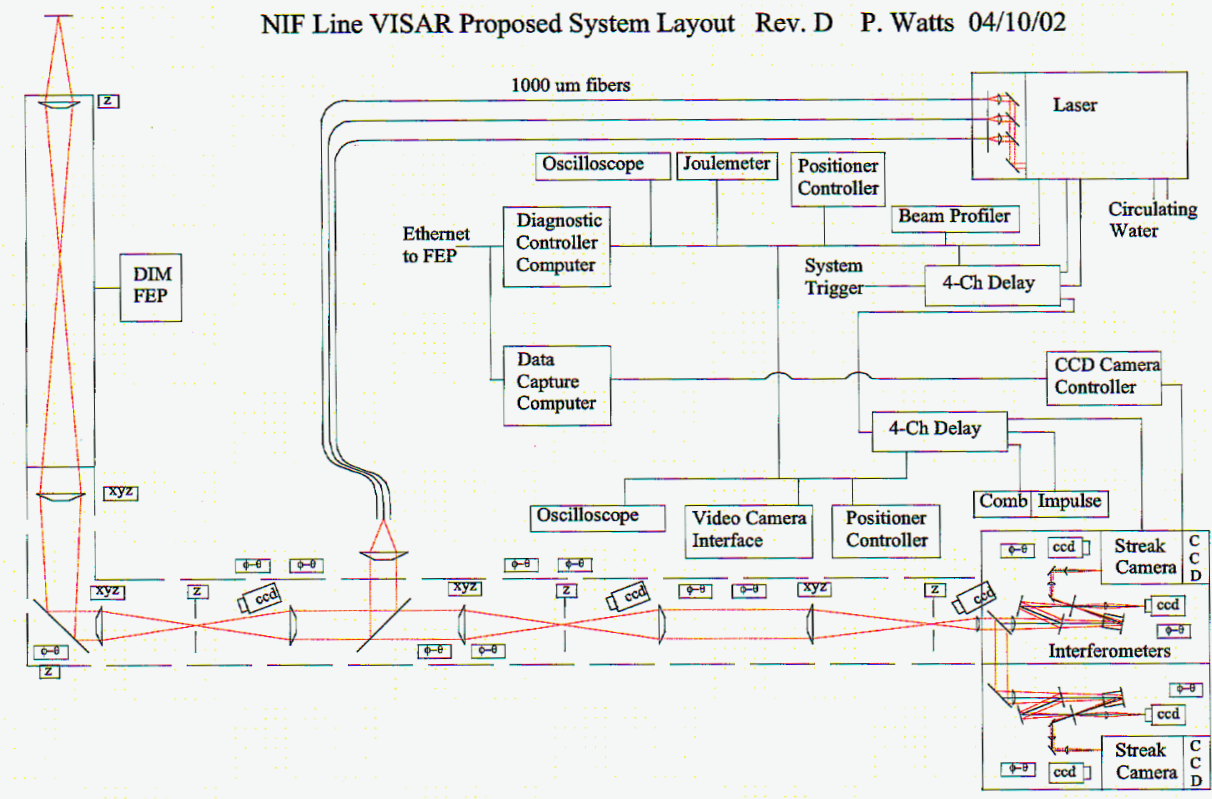

Figure 8: Conceptual layout of VISAR interferometer to be mounted in the polar DIM (shown at left) with the interferometer itself located at bottom right (proposed to be in the area above the Switch yard 2 diagnostic mezzanine).

\section{Neutron Yield Diagnostic (NYD)}

In the last quarter, the neutron yield diagnostic design team met with the diagnostic expert group to finalize the requirement specifications of the NYD. All parties involved, LLNL, LLE, LANL, SNL, BN-STL, were in agreement and resolved key questions regarding the diagnostic requirements. Shortly, with the help of Craig Sangster (LLE), the nuclear expert group leader, the final requirements will be documented and prepared for the approval process. The design team will also meet this quarter with personnel at LLNL to specifically address the interfacing of the diagnostic to the NIF facility. Shortly thereafter, we will start the initial design of the diagnostic in preparation for the CDR scheduled in September. Early progression to a conceptual design is intended to identify opportunities to reduce the facility impacts of the NYD sample transport system. 


\section{Target Diagnostic Integration}

Diagnostic integration works with the diagnostic designers to adapt the facility to meet their needs and help them integrate their diagnostics into the facility. There is a continuous interaction between the Integration Engineer and the NIF Project through the BIS Beampath and Infrastructure organization, the Architecture and Engineering firm, various Integrated Product Team leaders, and project management to make cost effective decisions.

To accommodate future FABS backscatter diagnostics, the target bay was modified to create four large openings in the floor at the 29'6'. This work required that the FABS beampath soft and hard stay-out zones were developed and frozen in order to locate and size the openings in the one-foot-thick concrete floor. Utilities were also relocated to accommodate the beampath.

Figure $9 \mathrm{a}$ below shows the FABS models that were used to locate the openings, and Figure $9 \mathrm{~b}$ shows one of the openings.

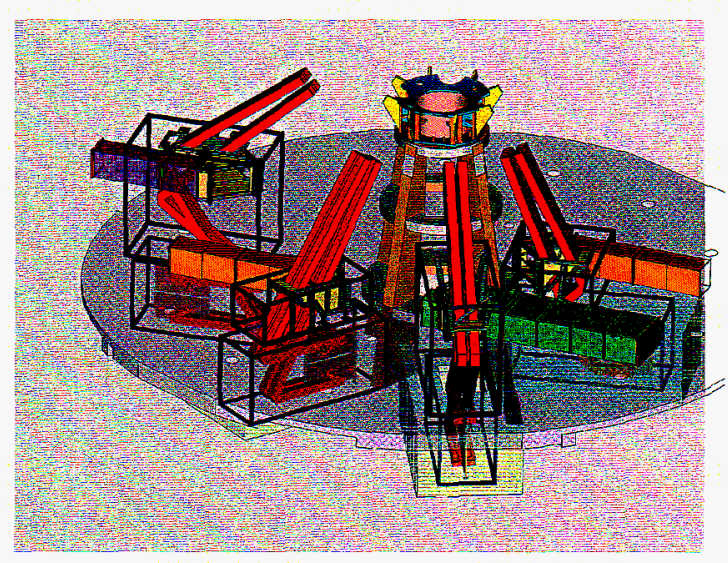

a)

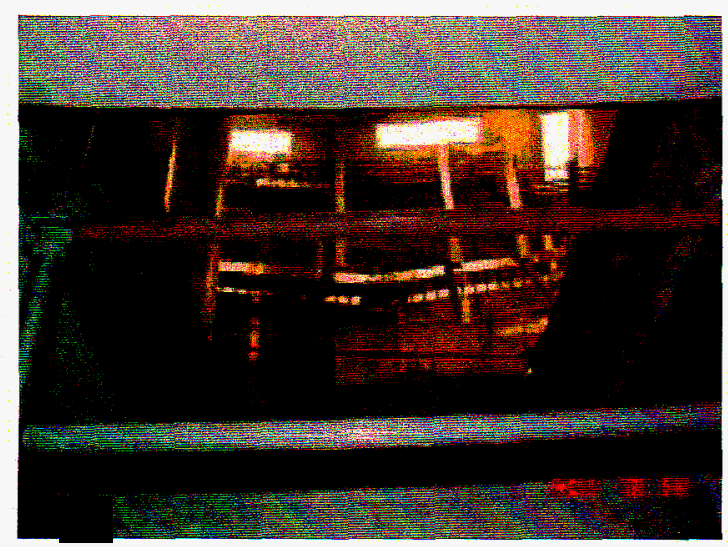

b)

Figure 9a) Schematic of the target area showing four locations prepared for future backscatter diagnostics, b) view through one of the holes cut in the floor of the target area to allow future installation of a backscatter diagnostic.

More minor modifications were designed and implemented to eliminate interference between the static $\mathrm{x}$-ray imager and the target chamber pedestal. This required scalloping the concrete at the target chamber pedestal and redesigning structural steel framing.

Integration of the VISAR into the facility involves the layout of an optical beampath for between the polar DIM and the interferometer location. A possible path was identified, and we are working with the optical designer at BN-Los Alamos to iterate to an acceptable solution. Figure 10a shows the beampath, and figure $10 \mathrm{~b}$ shows the stay-out zone for the interferometer table above the Switchyard 2 diagnostics mezzanine. 


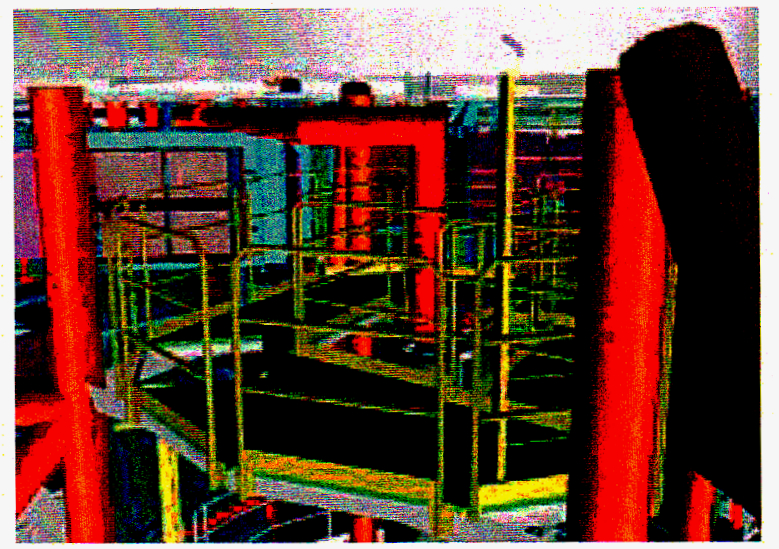

a)

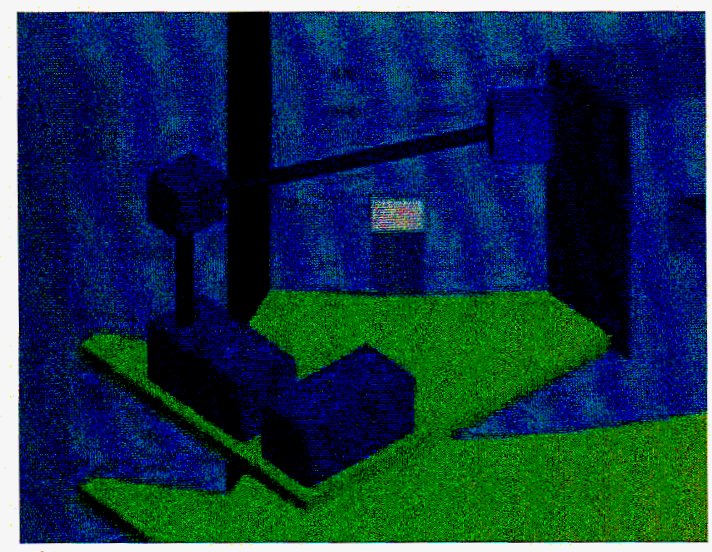

b)

Figure 10a) Illustration of the beampath for the VISAR interferometer showing the beam emerging from the back of the polar DIM, b) the routing of the VISAR beampath through the curved target bay wall into the area above the diagnostic mezzanine.

Efficient use of the polar DIM has required design of access platforms and a monorail crane above the DIM illustrated in Figure 11.

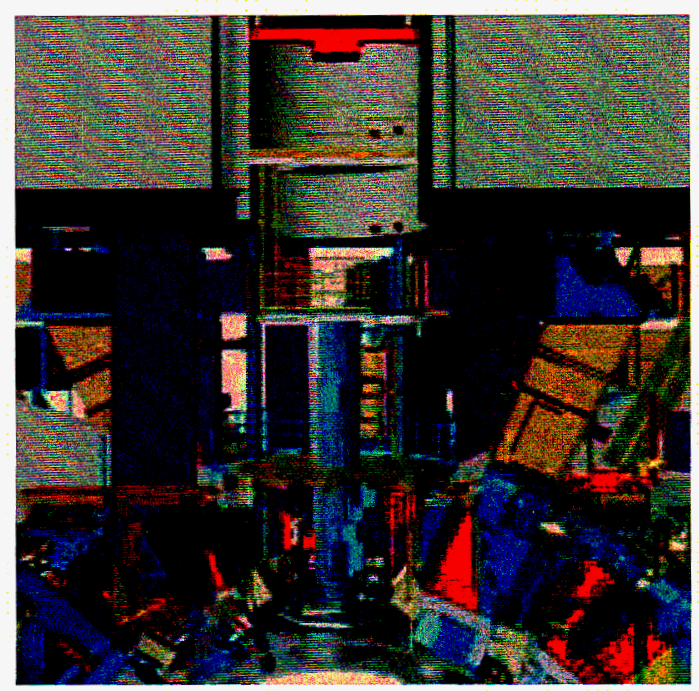

Figure 11: Support platforms and crane for servicing the Polar DIM. 


\section{Controls Integration}

Controls integration engineers negotiated with the NIF BIS team on the schedule for installing equipment in the diagnostic mezzanines (there are two of these areas outside the shield wall just inside the two switchyards). The rack/cable tray installation was divided into 3 phases. The phases are First Quad activation (September 2002), First Experiments activation (May 2003), and First Cluster activation (August 2004). The dates indicate when the racks and cable trays will be available. Based on this new plan, the DIM and diagnostics cabling required for First Quad were optimized. The NIF BIS team will include this new definition in their work package CSP15B.

We have released our NIF Diagnostic Communication Protocol (DCP) document (NIF 0051081). It is available through NIF PDM or the NNDP LIAM FTP site. The NIF Requirements and Recommendation for Diagnostic Controller (DC) Development document (NIF 0018678) was updated and sent out for review in February/March. A few minor comments, requests, and suggestions were provided by the reviewers. We are currently making minor modifications to the document before sending it out to the reviewers again.

While working on our first diagnostic controller for the SXI, we have experimented with different system architectures and programming techniques. We have settled on an internal standard, which can be applied to most diagnostics. A Front End Processor (FEP) emulator, Diagnostic Controller (DC) emulator, and a Generic Diagnostic Controller (GDC) will be made available to diagnostic developers in the future. The GDC is the code template that will be made available to diagnostic development teams. The FEP emulator will be provided as both a development tool and a DCP standard tester. 